\title{
MUDANÇAS CLIMÁTICAS E AQUECIMENTO GLOBAL: CONTROVÉRSIAS, INCERTEZAS E A DIVULGAÇÃO CIENTÍFICA
}

\author{
CASAGRANDE, Alessandro - alecasa@gmail.com \\ Programa de Pós-graduação em Meio Ambiente e Desenvolvimento / UFPR \\ SILVA JUNIOR, Pedro - pedrojrsilva@hotmail.com \\ Programa de Pós-graduação em Meio Ambiente e Desenvolvimento / UFPR \\ MENDONÇA, Francisco - chico@ufpr.br \\ Programa de Pós-graduação em Meio Ambiente e Desenvolvimento / UFPR
}

\begin{abstract}
Resumo. As mudanças climáticas globais, tema de forte interesse político-economico-ambiental do presente, compõem tema central de inúmeros e conflituosos debates contemporaneos. Este artigo trata das controvérsias e incertezas científicas acerca do aquecimento global em duas revistas impressas Ciência Hoje e Scientific American Brasil. Para tanto aplicou-se uma análise de conteúdo a textos publicados em duas revistas de divulgação científica editadas durante os meses de junho de 2009 a julho de 2010 - período anterior e posterior da Conferência do Clima de Copenhague -, considerado, historicamente, o marco da polêmica que polarizou o debate sobre o aquecimento global. O texto aborda também, com base na literatura acadêmica, o conceito de mudanças climáticas, efeito estufa e aquecimento global, bem como aponta as causas, naturais e antropogênicas, e dos efeitos do aquecimento global dentro da perspectiva da divulgação científica.
\end{abstract}

Palavras-chave: Aquecimento global; mudanças climáticas; divulgação científica

CLIMATE CHANGE AND GLOBAL WARMING: CONTROVERSIES, SCIENTIFIC UNCERTAINTY AND DISCLOSURE

Abstract. This paper discusses the scientific uncertainties and controversies about global warming in two printed magazines Ciência Hoje and Scientific American Brasil. It refers to two popular science magazines which the content analysis was performed during the period June 2009 to July 2010, before and after the Copenhagen Climate Change Summit in December, 2009 - which was considered historically the beginning of the controversy over the global warming debate. To achieve this goal, we reviewed the climate change, greenhouse effect and global warming concepts on the scientific literature, as well the survey of the causes, whether natural or anthropogenic-produced, and the effects of global warming from the perspective of science communication.

Keywords: Global warming; climate change; science communication.

\section{Introdução}

O bem-estar econômico e social dos seres humanos, apesar dos grandes avanços técnico-teconológicos observados na alta-modernidade, continua dependendo, em larga medida, de fatores climáticos, sendo bastante provável que esta dependência continue no futuro. Ainda que a lógica social do homem que vive no tempo-veloz pareça suplantar aquela do homem que vive no tempo-lento (SERRES, 2000), a grande maioria dos seres humanos é diretamente influenciada pelos ritmos do tempo e do clima, especialmente no contexto dos países não desenvolvidos.

No momento em que as mudanças climáticas são consideradas um fator de risco em face ao destino da humanidade - dentre os vários indicadores da sociedade de risco (BECK, 1998), a compreensão da divulgação científica sobre o aquecimento global torna-se um complexo desafio para se entender as diferentes posturas pessoais e institucionais acerca do tema. Afinal, este fenômeno esta realmente ocorrendo? Quais são as bases científicas convincentes para sua compreensão? Se está ocorrendo, seria causado pela ação do homem (contingência antropogenica)? Ou, refletiria 
ele apenas uma situação natural da atmosfera do planeta Terra (contingência natural)? Há fortes divergências sobre essa temática, pois é típico da comunidade científica reagir com um mixto de entusiasmo e de ceticismo quando novas ideias são lançadas.

Essa preocupação passou a ser reconhecida pela primeira vez no final dos anos de 1980, quando uma considerável parcela dos meteorologistas ficou preocupada com a possibilidade de que ações humanas, como o uso de combustíveis fósseis, pudessem estar contribuindo para o aquecimento global - intensificação da temperatura do planeta. Nessa mesma época, alguns cientístias chegaram a afirmar, apressada e alarmisticamente, que o problema se manifestaria dentro em breve e que poderia ter efeitos sociais, ecológicos e econômicos desastrosos. Tais crenças estavam fundamentadas, em parte, nos resultados dos modelos globais simulados por computadores de balizados centros de pesquisas da atmosfera do planeta (MILLER, 2008).

A constatação desse "novo risco" para o meio ambiente - o aquecimento global - e a crescente vulnerabilidade da sociedade aos seus efeitos levaram as Nações Unidas (ONU) a criar a Convenção do Clima, a partir das discussões e resultados da Rio-92. As duas últimas reuniões da Convenção do Clima foi a Conferência de Copenhague (realizada em dezembro de 2009) e a Conferencia do México (realizada em novembro de 2010). O primeiro evento, durante o qual foi divulgado o 40 Relatório do Intergovernamental Panel on Climate Chage (IPCC) - o AR-4, constituiu-se num dos mais importantes marcos a evidenciar a importância que o tema adquiriu no contexto das mais diversas instituições sociais em ambito internacional.

Considerando-se este contexto - de conflitos e interesses diversos (MAN YU, 2001; MENDONÇA, 2007), delimitou-se o objeto deste texto. A abordagem está centrada na analise da divulgação científica acerca das controvérsias científicas relativas ao risco do aquecimento global. Os textos de duas revistas de divulgação científica, a Ciência Hoje e Scientific American Brasil, constituem a base do estudo realizado, como se verá a seguir.

\section{Mudanças climáticas globais: A intensificação do aquecimento atmosférico da Terra}

A dinâmica climática é condicionada, primariamente, pela radiação solar, que é a fonte básica de energia para a Terra. Cerca de $30 \%$ dessa radiação são refletidos, imediatamente ao adentrar a atmosfera terrestre, de volta para o espaço, dos quais as nuvens são responsáveis pela metade (15\%) e os $15 \%$ restantes, pelos aerossóis e moléculas que compõem a atmosfera e pela superfície terrestre, sem produzir qualquer aquecimento. A proporção entre a radiação refletida e a incidente é chamada albedo, que é variável para diferentes tipos de superfície a exemplo dos oceanos - cerca de $10 \%$, e a neve e o gelo - em torno de $90 \%$ (LINO, 2009, p.8). 
Além da radiação solar, um processo natural chamado "efeito estufa" aquece a baixa troposfera, junto à superfície terrestre e na qual a vida biológica se desenvolve. O químico sueco Svante Arrhenius (1859-1927) foi o primeiro a reconhecer esse efeito natural de aquecimento da troposfera, em 1896; a partir de então, muitas experiências de laboratórios e medições das temperaturas atmosféricas em diferentes altitudes confirmaram essa relação; "Hoje ela é uma das mais aceitas teorias das ciências atmosféricas" (MILLER, 2008, p. 421).

O efeito estufa tem esse nome por ser semelhante ao que ocorre em estufas de jardinagem, nas quais a cobertura de vidro permite a passagem da radiação solar e dificulta a perda de calor. Segundo Maruyama (2009 p. 37), sem o efeito estufa natural, a vida como é conhecida não seria possível na Terra, já que a temperatura média do planeta seria negativa (cerca de $-18^{\circ} \mathrm{C}$ ). Esse processo natural se dá quando a radiação terrestre é absorvida pelo vapor d'água, nuvens e gás carbônico - responsáveis por cerca de $90 \%$ do efeito estufa; a parcela restante cabe ao metano, ozônio, óxido nitroso e outros gases, como o clorofluorcarbono. Esses gases, por sua vez, emitem a radiação terrestre em todas as direções, inclusive em direção à superfície e ao espaço. A absorção e emissão desses gases pelas várias camadas atmosféricas reduz a perda de radiação terrestre, emitida pela superfície, que escaparia para o espaço exterior (MOLION, 2008). Nesse sentido, e de acordo com Mendonça e Danni-Oliveira (2007, p. 183), o efeito estufa "decorre da interação de componentes da Troposfera com a energia emitida pela superfície terrestre ao se resfriar $(\ldots)$ ".

De acordo com Miller (2008, p. 420), as mudanças climáticas no planeta Terra "não são nem novas nem incomuns". Durante os últimos 4,5 bilhões de anos o clima do planeta foi alterado por emissões vulcânicas, mudanças na intensidade solar, movimentos dos continentes em razão do deslocamento das placas tectônicas, choques com grandes meteoros, etc. (MILLER, 2008).

Durante os últimos $900 \mathrm{mil}$ anos a temperatura média da troposfera terrestre passou por longos períodos de resfriamento e de aquecimento, ciclos alternados que configuram períodos glacial e interglacial. As mudanças de temperatura no âmbito da paleoclimatologia são estimadas por análise de radioisótopos em rochas e fósseis, plâncton, núcleos de gelo de geleiras antigas, medições de temperatura tomadas em diferentes profundidades por meio de perfurações, esporos de fungos encontrados em lagos e brejos, anéis de crescimento de árvores e medições de temperatura (AYOADE, 1986; DIAMOND, 2001; RUDDIMAN, 2003).

Uma mudança climática, de qualquer dimensão e resultando em aquecimento ou resfriamento global, por ser algo tão ampla e complexa, afetará de maneira geral todos os componentes do sistema-Terra (MENDONÇA, 2007). É por isso que não se deve pensá-la dissociadamente do sistema-mundo, pois não há como imaginar que uma mudança desta magnitude, lenta ou brusca, não afetará a forma como as sociedades e as pessoas ocupam o espaço. Dentre as várias questões postas às ciências e à sociedade, pode se destacar: Que mudanças e que impactos naturais e 
sociais, portanto para o planeta e para a humanidade, provocariam as mudanças climáticas globais?

O aquecimento global pode ter vários efeitos, tanto benéficos quanto nocivos, para os seres humanos, outras espécies e ecossistemas, dependendo, principalmente, do local e da magnitude da mudança climática (MENDONÇA, 2007). Algumas regiões se beneficiariam com mais precipitações, invernos menos rigorosos, menos chuvas em áreas úmidas e elevação da produção de alimentos. Ademais, várias espécies de animais e plantas adaptadas a temperaturas mais altas poderiam expandir suas populações e áreas de ocorrencia (MENDONÇA \& DANNI-OLIVEIRA, 2007). Outras áreas sofreriam prejuízo com o calor desmedido, escassez de água e alimentos. É provável que os incêndios florestais sejam mais recorrentes, especialmente nas áreas de campos, onde o clima ficaria mais seco, e aumentariam as mortes de árvores pelo aumento das doenças e das pragas que floresceriam em áreas com clima mais quente. Muitas espécies de animais e plantas que não podem migrar ou se adaptar a temperaturas mais altas poderiam sofrer redução de sua endemicidade, perdas populacionais e eventualmente extinção prematura.

Em determinadas regiões os efeitos ameaçariam muitos parques, reservas de animais selvagens e recifes de corais; ao contrário, as espécies com mais probabilidade de florescer em um ambiente mais quente incluem certas ervas daninhas de rápida multiplicação, insetos nocivos e organismos que transmitem doenças, como mosquitos e bactérias transportadas pela água.

\section{Controvérsias e incertezas científicas sobre $o$ aquecimento global}

Weart (2010) afirma que os climas da Terra são controlados por variações previsíveis na órbita da Terra em volta do Sol; essas variações são conhecidas como Ciclos de Milankovitch e operam a cada $100 \mathrm{mil}, 41 \mathrm{mil}$ e 22 mil anos, controlando a quantidade de radiação solar que chega a diferentes partes do globo numa dada estação do ano, que pode diferir em mais de $10 \%$ uma da outra. Ao longo dos últimos 3 milhões de anos, essas mudanças regulares na quantidade de luz solar que incide sobre o planeta têm produzido uma série de eras glaciais, separadas por períodos interglaciais curtos e quentes (RUDDIMAN, 2001).

Sequências climáticas desse tipo aconteceram durante milhões de anos, período no qual os hominídeos primitivos evoluíram lentamente para humanos anatomicamente modernos. No fim do período glacial mais recente, as calotas de gelo que congelaram o norte da Europa e a América do Norte durante os $100 \mathrm{mil}$ anos anteriores encolheram, desaparecendo há cerca de 6 mil anos. Muitos cientistas creditam boa parte do progresso da civilização a esse intervalo naturalmente quente entre as glaciações (DIAMOND, 2001).

A partir do final da década de 1980, entretanto, alguns estudos científicos passaram a considerar outras questões, além daquelas citadas nos parágrafos anteriores, que podem interferir nas mudanças climáticas, o 
que vem gerando divergências na concepção e abordagem do fenômeno (MENDONÇA, 2007). Atualmente, as principais controvérsias e incertezas sobre as mudanças climáticas e o aquecimento global podem ser resumidas em quatro posições: 1) A referência à participação antropogênica no aquecimento global; 2) A possibilidade (ou não) de amenizar esse fenômeno climático e como isso deve ser realizado; 3) A temporalidade dos efeitos do aquecimento sobre a sociedade e o meio ambiente; 4) A severidade desses efeitos.

A respeito da primeira questão, é reconhecido que o IPCC Intergovernamental Panel on Climate Change - é a fonte de informação de maior visibilidade na esfera pública referente ao tema "aquecimento global". O Painel, criado em 1988, tem como objetivo fornecer, tanto a quem toma as decisões políticas quanto aos demais interessados, informações objetivas sobre as mudanças climáticas. Além disso, o IPCC afirma que a causa principal do aquecimento da atmosfera é a emissão de dióxido de carbono ( $\mathrm{CO} 2$ ) e outros gases resultantes da queima de combustíveis fósseis que, lançados na atmosfera, intensificam o efeito estufa.

Conforme o $4^{\circ}$ Relatório divulgado pelo IPCC, "o entendimento sobre as influências antropogênicas de aquecimento e resfriamento no clima melhoraram desde o 30 Relatório, levando a uma confiança muito grande que a média do efeito global das atividades humanas desde 1750 têm sido de aquecimento $[\ldots] "$. Além disso, foi constatado que a população e a industrialização no mundo aumentaram consideravelmente $e$, por consequência, os níveis de $\mathrm{CO} 2$ na atmosfera vem crescendo e influenciando na manutenção do efeito estufa. Ademais, para o IPCC, o gás carbônico é o responsável pelo aumento da temperatura média global considerando que "a maior parte do aumento das temperaturas médias globais observadas desde meados do século XX é muito provável [segundo a classificação do Painel, acima de $90 \%$ ] que seja devido ao aumento observado nas concentrações de gases de efeito estufa antropogênicas" (IPCC - AR4, 2007, p. 665).

Esse mesmo relatório contestou a tese de que as emissões naturais possivelmente não são a causa do aquecimento global e que a

grande difusão observada do aquecimento da atmosfera e oceanos, juntamente com a perda de massa de gelo, apóiam a conclusão de que é extremamente pouco provável que a mudança climática global nos últimos 50 anos possa ser explicada sem forças externas, e muito provável que não seja devido apenas a causas naturais conhecidas (idem, ibidem). 
Ao contrário dessa perspectiva, pesquisadores como Lomborg (2002), Leroux (2007), Molion (2008), Maruyama (2009), Baptista (2009) 1 , consideram que o aquecimento global não pode ser atribuído à ação antropogênica. Para esses cientistas, a grande quantidade de dióxido de carbono enviada à atmosfera pelas florestas em decomposição e pelos oceanos também contribui em muito nas mudanças climáticas; o principal argumento deles apóia-se na tese de que a Terra passou por outros períodos de aquecimento antes da Era Industrial, e não se conhece com certeza os agentes que os provocam (BAPTISTA, 2009).

Nessa mesma linha de pensamento, Maruyama (2009) pondera que o fato de a teoria do $\mathrm{CO}_{2}$ ser a causadora do aquecimento global arraigou-se na mente das pessoas pela adoção da mídia internacional a uma teoria frouxa, sem questionar outras possibilidades como a intensificação das atividades solares dos últimos 400 anos. Ademais, Molion (2007) critica a visão do IPCC e considera que o clima do planeta varia de maneira natural ao longo de sua existência, forçado por agentes, quer externos - como oscilações das atividades solar e vulcânica, e dos parâmetros orbitrais terrestres quer internos - como variação da temperatura de superfície dos oceanos e cobertura de nuvens. Isso se deve, porque o clima nunca é estável, que nunca permaneceu em equilíbrio; Uma de suas constatações é que pesquisadores, como Monte e Harrison Hierb, concluíram "que mais de $97 \%$ das emissões de gás carbônico são naturais, provenientes dos oceanos, vegetação e solos, cabendo ao homem menos de 3\%", evidenciando que a influência das emissões antrópicas é muito pequena.

Os argumentos da segunda controvérsia sobre as mudanças climáticas são os seguintes: O IPCC aponta que o passo inicial é reduzir as emissões de $\mathrm{CO}_{2}$ para a atmosfera e que, depois disso, é necessário aumentar a eficiência no uso de energia alternativa para queimar menos combustíveis fósseis. Os estudos do Painel apontam que, do período pré-industrial (início do século XVIII) à década de 1990, a concentração do dióxido de carbono na atmosfera aumentou em 25\%. Em menos de cem anos, a temperatura média da Terra subiu $0,5^{\circ} \mathrm{C}$.

1 Em 2007, um grupo de cem pesquisadores assinaram a Carta Aberta ao Secretário da ONU na qual colocam em dúvida a hipótese que o aquecimento global seja induzido pelo homem. 
Para exemplificar o argumento acima, pode-se citar o "taco de hóquei" gráfico da temperatura do último milênio que mostra a influência drástica dos humanos no século $X X$, ou seja, a temperatura é a mesma até meados de 1900, então sobe de repente, como a curva da lâmina de um taco de hóquei - proposto por Michael Mann, e que ganhou proeminência no sumário executivo do 30 Relatório do IPCC em 2001. O Painel elevou o "taco de hóquei" ao status de ícone e também de alvo 2 , mas um grupo de cientistas céticos atacou os dados utilizados por Mann, considerando-os esparsos demais para constituir um quadro realista.

Para a terceira divergência, o Painel Climático avaliou que os primeiros sinais do aquecimento global já estão presentes, tais como as secas nos continentes, a intensificação de ciclones, grandes nevascas e tempestades etc., e ainda, conforme os modelos de simulação, há a previsão de que o nível dos mares deve subir, em média, 38 centímetros até o final desse século, o que poria as cidades costeiras em risco. Contrariando o IPCC, Lomborg (2002) considera que a atual elevação do nível dos mares está dentro da oscilação característica dos últimos 300 anos; no século $\mathrm{XX}$, por exemplo, o nível dos mares cresceu 20 centímetros sem nenhum efeito perceptível.

Todavia, os pesquisadores do IPCC alertam que, apesar de já terem cerca de $95 \%$ de certeza de que o aumento de $0,5^{\circ} \mathrm{C}$ na temperatura do planeta seja de ordem antropogênica, as previsões de suas repercussões constituem, ainda, apenas probabilidades.

Por fim, quanto ao grau de severidade do aquecimento global, o pressuposto do IPCC é de que as catástrofes naturais serão mais frequentes e devastadoras, pois os levantamentos estatísticos que monitoram as imagens de satélites mostram que a massa glacial do planeta vem se reduzindo progressivamente com o derretimento de geleiras. Outros pesquisadores discordam, pois acreditam que os desastres serão poucos e a humanidade não terá dificuldade para se adaptar a essas alterações climáticas. De acordo com Akasofu (2005), a redução das camadas de gelo marinho e dos glaciares foi observada de forma sistemática em algumas áreas da Terra, mas há poucos estudos sobre a espessura e a profundidade das geleiras, considerando com isso baixo o índice de risco para a humanidade.

Akasofu (2005) ainda destaca que as variações recentes (desde 1800) das temperaturas resultaram da sobreposição de dois fenômenos naturais: um ligeiro aquecimento devido ao final da Pequena Idade do Gelo (entre 18001850); e cinco oscilações multidecenais - subidas e descidas em relação à média - resultantes de causas naturais que se sobrepuseram àquele ligeiro aquecimento.

Nobre (2010) rebate as criticas desferidas contra as afirmações do IPCC, considerando que elas

2 Disponível em: www.realclimate.org, acesso em 10 de julho de 2010. 
servem de impulso para os céticos porque eles não conseguem trazer qualquer fato científico novo, surpreendente, que coloque realmente em dúvida a ciência robusta e sólida do aquecimento global [...]. Todo esse alvoroço e os questionamentos sobre a legitimidade do órgão são mais uma jogada política de quem é contra a agenda climática. Mas essas coisas duram muito pouco, porque a força da ciência é tremenda [...]. Quem faz avançar a ciência do clima não é o IPCC. Quem faz avançar a ciência do clima é a ciência. O IPCC só sumariza resultados. E ao fazer esse sumário, o IPCC não é infalível, como nenhuma instituição científica é infalível.

Como se observa, não há consenso entre os pesquisadores com relação às causas e às consequências climáticas do aquecimento global; a despeito deste contexto de conflitos e jogos de interesses, parece importante considerar que há uma complexidade no cenário dos "processos que envolvem a interação oceano-atmosfera" (MENDONÇA \& DANNI-OLIVEIRA, 2007, p. 188). A ciência da atmosfera está em fase de consolidação em muitos lugares do mundo e, fenômenos que ora são de compreensão duvidosa, poderão ser melhor esclarecidos dentro em breve.

\section{Aquecimento global e mudanças climáticas na divulgação científica}

A breve contextualização do tema acima exposta permite avançar para uma análise do enfoque sobre o aquecimento global no corpus das revistas de divulgação; científica Ciência Hoje e Scientific American Brasil, nas edições publicadas de junho 2009 a julho de 2010, objetivo principal deste texto. Desta analise poder-se-á observar, de maneira introdutória, as perspectivas veiculadas na mídia científica acerca das mudanças climáticas globais.

Neste item, para a definição de divulgação científica buscou-se aporte em Bueno (1984), que a considera como sendo a utilização de recursos, técnicas e processos para a veiculação de informações científicas e tecnológicas ao público em geral, presupondo uma decodificação da linguagem especializada para não-especializada. Dessa forma, a divulgação científica faz coincidir com o jornalismo científico que é, em última instância, uma modalidade de difusão científica. Para Bueno, a divulgação científica 


pelos meios de comunicação promove a
democratização do conhecimento científico,
ampliando o debate sobre temas relevantes de
ciência e tecnologia. [...] Esta função se reveste de
caráter político (não partidário) no seu sentido mais
amplo porque favorece a explicitação dos interesses
envolvidos no financiamento, produção e aplicação
da ciência e da tecnologia 3 .

As revistas Ciência Hoje e Scientific American Brasil cumprem essa função, e ambas têm como linha editorial um tipo de divulgação científica hard, ou seja, aquele que prioriza as ciências biológicas, exatas e tecnológicas, abordando de forma consistente e didática, assuntos que, em geral, não são tão familiares aos leigos.

\section{III.1 Procedimentos Metodológicos}

Diante da impossibilidade prática de acompanhar a veiculação de informações sobre o aquecimento global em todos os veículos de divulgação cientítica, dado o grande número de textos sobre o tema, optou-se por trabalhar com duas importantes revistas do meio científico, Ciência Hoje e Scientific American Brasil.

A revista Ciência Hoje é um veículo ligado à Sociedade Brasileira para o Progresso da Ciência (SBPC) e foi lançada no ano de 1982. A valorização da divulgação da pesquisa nacional é o objetivo principal dessa revista, que "adota um sistema de arbitragem por pares, tal como utilizado por revistas técnicas especializadas como forma de avaliação dos artigos a serem publicados" (LIMA, 1992, p. 93).

A Scientific American Brasil foi criada em 1845 nos Estados Unidos, e sua versão brasileira foi lançada em 2002. Como ocorre geralmente com as adaptações de revistas estrangeiras, a maior parte dos textos é traduzida da versão estadunidense, cuja importação de conteúdos, porém, acarreta uma redução expressiva do espaço destinado às pesquisas nacionais.

As duas revistas selecionadas publicam algumas matérias assinadas por cientistas, em geral, as principais, e outras por jornalistas. Assim, apesar de serem publicações de divulgação de ciência, elas desfrutam de um prestígio típico de revistas científicas. Isso significa que um artigo acadêmico publicado nas páginas de Ciência Hoje e Scientific American Brasil constitui uma forma de reconhecimento da qualidade e credibilidade de ambas.

A pesquisa mapeou os conceitos, as definições e controvérsias sobre o aquecimento global como exemplo de risco ambiental; e identificou os

3 BUENO, W. C. Jornalismo científico e democratização do conhecimento. Disponível em: $\quad<$ http: //www.jornalismocientifico.com.br/jornalismocientifico/artigos/jornalismo_cientifico/artigowilb uenojcdemocratizaconhecimento.htm>. Acesso em 10/07/2010. 
gêneros (artigos, entrevistas, colunas, notas, opinião etc.) e as fontes de informação envolvidas nos textos das duas revistas; o enfoque especial recaiu no questionamento acerca da gênese do aquecimento global. A investigação está embasada na análise de conteúdo, com a classificação das significações do discurso em categorias (BARDIN, 2006).

Após esse levantamento, a análise dos textos (ou gêneros) obedeceu aos seguintes critérios: na primeira parte, quantitativamente, apontou as fontes e seus discursos científicos sobre os riscos do aquecimento global; em seguida, apontou o discurso das controvérsias científicas da temática publicada nas revistas a partir do seguinte questionamento: o aquecimento global divulgado é natural ou causado pelas atividades humanas?

A análise de conteúdo sobre o aquecimento global foi realizada em todas as seções das revistas escolhidas, com exceção das cartas de leitores, que não se enquadram no universo da pesquisa. Foram selecionados os diferentes gêneros jornalísticos (artigo, editorial, entrevista, nota, reportagem, resenha etc.) que citam nominalmente a temática aquecimento global, e também aqueles textos que, mesmo não o citando explicitamente, fazem referência às mudanças climáticas e ao efeito estufa. O levantamento dos textos envolveu a análise de todos os exemplares publicados no período de junho de 2009 a julho de 2010, tendo sido selecionados 13 edições e 06 gêneros da revista Scientific American Brasil; e 05 edições e 06 gêneros da Ciência Hoje, totalizando 36 textos, com diferentes tipos de informação.

Dentre as diversas fontes de informação que embasam os documentos analisados destacam-se aquelas diretamente de pesquisadores - com 35\%, o IPCC - $27 \%$, e o governo dos Estados Unidos - $13 \%$, este referenciado apenas na Scientific American Brasil. A qualificação dos autores deixa em evidencia 0 grupo de pesquisadores (biólogos, climatologistas, meteorologistas, médicos etc.) com $50 \%$ dos textos publicados nas duas revistas, seguido pelos jornalistas, economistas e outros, em número bem inferior àqueles.

\section{III.2 Aquecimento Global: Genese natural ou antropogênica?}

$\mathrm{Na}$ identificação e análise dos temas abordados nos textos observou-se alguns desmembramentos temáticos, classificados conforme as significações do discurso em categorias, cujos critérios são orientados pela dimensão da análise em questão (BARDIN, 2006). Dividiu-se, portanto, a amostra de artigos em unidades de significado, ou unidades que expressavam um sentido em si mesmo, e também referente ao contexto. Identificadas as diferentes unidades de significado, foram então eleitas as categorias temáticas que englobassem e expressassem o conteúdo e as mensagens implícitas contidas no texto. As categorias elencadas foram: aquecimento global por causa natural e aquecimento global por causa antropogênica. 
A analise do gráfico 1 revela, de maneira bastante clara, que a grande maioria dos documentos analisados tem por concepção básica aquela que afirma que o aquecimento climático global é provado sobretudo pelas atividades humanas, ou seja, embasa-se na concepção defendida pelo IPCC; $87 \%$ das informações que dão base aos textos está alicerçada sobre a crença de que o aquecimento climático global é provocado pelas atividades humanhas.

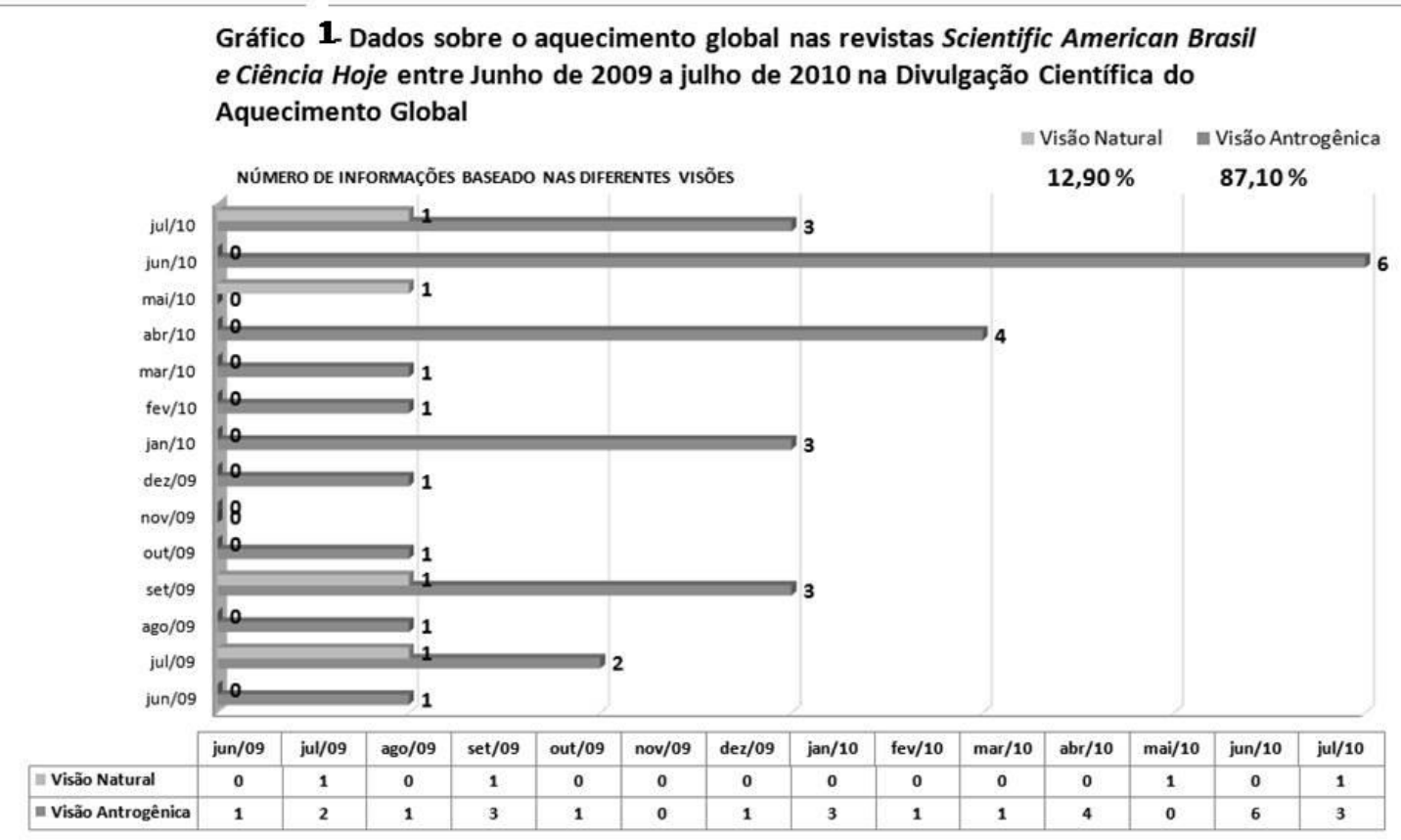

Fonte: Scientific American Brasil e Ciência Hoje, edições de jun./2009 a jul./2010.

Esta categoria - da gênese antropogenica do aquecimento global hegemônica nos textos das duas revistas analisadas, sugere, conforme os dados dos relatórios do IPCC, que a ação do ser humano como modificador do clima, em escala global ou planetária, tem se dado de várias maneiras alterando tanto a composição quanto o dinamismo da atmosfera.

Os documentos analisados são bastante claros ao tratar da temática e explicitarem as bases de suas afirmações, como se pode verificar nos exemplos a seguir, parte de textos extraídos daqueles: 
"O processo de aquecimento global está relacionado ao chamado 'efeito estufa'. [...] $O$ 'aquecimento global' acontece porque o equilíbrio natural desses gases vem sendo alterado por ações humanas, em especial a queima de combustíveis derivados de petróleo e a destruição das florestas. A liberação em excesso dos 'gases-estufa' exarceba o efeito estufa e altera o clima mundial, com efeitos imprevisíveis" (Revista Ciência Hoje, jul./2009, p. 24).

"A humanidade não está interferindo apenas nos níveis de carbono no ar, mas também nos de nitrogênio. Embora a queima de combustíveis fósseis seja conhecida por liberar óxidos de nitrogênio que podem fertilizar excessivamente ecossistemas ou reagir com outros compostos para formar smog e chuva ácida, os pesquisadores encontram dificuldade em identificar a extensão da interferência antropogênica nos níveis de nitrogênio da atmosfera" (Revista Scientific American Brasil, set./2009, p. 20).

Por outro lado, mas em número bastante inferior, aparecem 12,9\% de informações para as quais o processo de mudanças climáticas do presente responde, sobretudo, aos ciclos da própria natureza do planeta. Esta categoria tem por base a tese de que durante sua história natural, a Terra experimentou períodos de aquecimento e resfriamento. Como discutido anteriormente, há várias fontes que afirmam que a troposfera está ficando mais quente devido aos efeitos naturais, tais como as emissões vulcânicas, mudanças na intensidade solar, movimentos dos continentes em razão dos terremotos etc.

Parte de dois dos textos elaborados nesta vertente, e reproduzidos a seguir, ilustram o tipo de discurso que se enquadra nessa categoria:

"Elevação do nível do mar na era do gelo levanta questões sobre derretimento das geleiras. Graças à longa estabilidade geológica da ilha Maiorca, as cavernas registram os níveis do mar das últimas dezenas a centenas de milhares de anos na forma de estruturas de pedras. Ao examinar essas formações rochosas, uma equipe de geólogos concluiu que, em comparação com os dias de hoje, o nível do mar estava aproximadamente 1 metro mais alto há 81 mil anos, quando o mundo supostamente passava por uma era do gelo que teria aprisionado água no gelo glacial" (Revista Scientific American Brasil, maio/2010, p. 15).

"[...] Dados consistentes sobre indicadores de mudanças do clima ainda são escassos" (Revista Ciência Hoje, jul./2010, p. 33).

Essas foram as categorias temáticas destacadas, e que abrangem o conteúdo dos textos da amostra de artigos analisada. Uma questão importante a ser considerada refere-se às incertezas das duas correntes pois, se por um lado, como ficou constatado, o sistema climático da Terra é altamente não linear e sua completa modelização constitui ainda um desafio para a ciência, por outro, a própria dinamicidade do conhecimento científica coloca em questão a idéia de verdades absolutas. 
A representatividade dos diferentes segmentos analisados nas revistas e envolvidos na questão do aquecimento global e mudanças climáticas, acaba deslocada para os representantes da Ciência, vista como uma entidade suprema, aquilo que Morin (1996) chama de "Ciência Farol", uma instância que ilumina a humanidade e, portanto, tem poder sobre o seu rumo.

A bipolarizado que envolve a temática, conforme acima exposto, não aparece de forma explictia nos textos selecionados; os argumentos trocados entre os dois segmentos revelam-se, finalmente, bastante fracos e levam à uma idéia de esterilidade do debate no que concerne o progresso do conhecimento. Entretanto, a intensidade da controvérsia revela todo o interesse que as questões concernentes à ciência, sua organização e sua própria essência suscitam no seio do corpo social.

\section{Considerações finais}

O enfoque sobre o aquecimento global divulgado nas revistas Ciência Hoje e Scientific American Brasil não revela uma postura consensual única e homogênea de instituições e cientístas, apesar de que a grande maioria das posições é favorável ou partidária à tese do IPCC, para quem o fenômeno tem uma gênese sobretudo antropogênica.

Por outro lado os documentos analisados permitem inferir que os relatórios oficiais podem ser considerados incertos em suas conclusões, pois utilizamse de expressões como "muito provavelmente", "sugere", "existem evidências", (MARUYAMA, 2009, p.78). Ainda que seja a perspectiva majoritária nos textos analisados, há outras teorias científicas que contradizem a posição do IPCC, como, por exemplo, a influência das manchas solares, dos raios cósmicos, da variação do campo geomagnético terrestre e da mecânica celeste (LINO, 2009; MARUYAMA, 2009).

Nos textos analisados observou-se que a literatura científica sobre mudanças climáticas associada aos relatórios do IPCC é a mais evocada. Em contrapartida, pode-se notar o número exíguo de artigos na divulgação científica que considera a mudança climática e o efeito estufa como um processo natural, até porque poucos cientistas não acreditam na responsabilidade humana na produção do aquecimento global e duvidam de seus efeitos.

Quando se comparam as conclusões do IPCC e a posição dos chamados pesquisadores céticos, a grande dúvida que sobressai diz respeito à gravidade dos efeitos. Aqueles que são contrários ao Painel da ONU consideram que não existem dados suficientes para afirmar que os efeitos serão catastróficos a ponto de pôr em perigo a vida na Terra.

Embora as duas correntes não neguem a mudança climática, parece perfeitamente plausível que esteja acontecendo, ou que irá acontecer, um efeito sobre o aquecimento por conta das altas concentrações de gases de efeito estufa. Porém, as provas não são claras ainda; houve, por exemplo, períodos de aquecimento no século XIX quase idênticos ao modesto aquecimento que a Terra experimentou desde 1975. Não se pode confiar 
completamente nos atuais modelos climáticos como base para iniciativas políticas que custam bilhões e mudam a forma como a população vive.

Para isso, sugere-se um registro acurado como apontou o climatologista Yoshio Manabe, colaborador do General Circulation Model - complexo modelo matemático de circulação geral da atmosfera e (ou) do oceano, ao considerar que os supercomputadores atuais teriam que ser capazes de simular a complexidade do Sistema Solar para um diagnóstico mais fiel das mudanças climáticas (MARUYAMA, 2009).

Por fim, há que se considerar a estreita relação entre mudanças climáticas e preservação ambiental. O ritmo da perda do capital natural, que dá sustentabilidade a todas as formas de vida e economias, precisa ser revisto por meio de acordos internacionais, políticas públicas para o meio ambiente, mudanças nos padrões de do consumo, redução da poluição ambiental, etc. Mesmo assim, diante das controvérsias e incertezas sobre o aquecimento global, uma das mais graves ameças em que incorre a humanidade parece estar ligada ao progresso "cego" e incontrolado do conhecimento científico simplificado.

Apesar dos céticos do clima dizerem que a conclusão de que o mundo está mais quente agora do que em qualquer período dos últimos mil anos seja discutível, não há dúvidas de que a degradação ambiental foi acelerada nas últimas décadas.

A questão da mudança climática é um desafio complexo na sociedade do risco (BECK, 1998), pois envolve o que ficou conhecido como "paradoxo de Giddens": "Visto que os perigos representados pelo aquecimento global não são palpáveis, imediatos ou visívei no decorrer da vida cotidiana, por mais assustadores que se afigurem, muita gente continua sentada, sem fazer nada de concreto a seu respeito. No entanto, esperar que eles se tornem visíveis e agudos para só então tomarmos medidas sérias será, por definição, tarde demais" (GIDDENS, 2010, p. 20).

\section{REFERÊNCIAS}

.AKASOFU, S.-I. Comment on the extreme magnetic storm of 1-2 September 1859. Journal of Geophysical Research, 110(A09226), doi:10.1029/2005JA011005, 2005.

.AYOADE, J. O. Introdução à climatologia para os trópicos. Rio de Janeiro: Bertrand Brasil, 1986.

.BAPTISTA, G. M. M. Aquecimento global: ciência ou religião? Brasília: Hinterlândia, 2009.

.BARDIN, L. Análise de Conteúdo. Lisboa: Edições 70, 2006.

.BECK, Ulrich. La sociedad del riesgo: hacia una nueva modernidad. Barcelona: Paidós, 1998.

.BUENO, W. Jornalismo científico no Brasil: aspectos teóricos e práticos. São Paulo: Escola de Comunicações e Artes da USP, 1988.

.DIAMOND, J. Armas, germes e aço. Rio de Janeiro: Record, 2001.

.GIDDENS, A. A política da mudança climática. Rio de Janeiro: Zahar, 2010.

.IPCC TAR, 2001 In: SINGER, Fred S. Nature, Not Human Activity, Rules Climate: Summary for Policymakers of the Report of the Nongovernmental International Panel on Climate Change. $1^{\text {a }}$ ed. Chicago: The Heartland Institute, 2008.

.IPCC AR4/SPM, 2007. Contribution of Working Group I for the Fourth Assessment Report (AR4), Summary for Policy Makers (SPM), WMO/UNEP, Genebra, Suiça.

.LEROUX, M. Aquecimento global: uma impostura científica. Disponível em: http:/www.resistir.info/climatologia/impostura_cientifica.html, acesso em 30 de maio de 2007. 
.LIMA, M. Ciência Hoje nas bancas. Dissertação (Mestrado). Programa de Pós-Graduação em Comunicação Social, Instituto Metodista de Ensino Superior, São Bernardo do Campo, 1992.

.LINO, G. L. A fraude do aquecimento global: Como um fenômeno natural foi convertido numa falsa emergência mundial. Capax Dei, Rio de Janeiro, 2009.

.LOMBORG, B. O ambientalista cético. São Paulo: Campus, 2002.

.MAN YU, C. et al. A intensificação do efeito estufa planetário e a posição dos países no cenário internacional. Revista Ra'e Ga - $\mathbf{O}$ espaço geográfico em análise. Curitiba/UFPR, Editora da UFPR, n. 5, ano 5, 2001. Pg. 99-124.

.MARUYAMA, S. Aquecimento Global? São Paulo: Oficina de Textos, 2009.

.MENDONCA, F. A. Aquecimento global e suas manifestações regionais e locais:

Alguns indicadores da região Sul. Revista Brasileira de Climatologia, v. 2, p. 71-86, 2007. .MENDONÇA, F.; DANNI-OLIVEIRA, I. M. Climatologia: noções básicas e climas do Brasil. São Paulo: Oficina de Textos, 2007.

.MILLER, G. Tyler. Ciência ambiental. São Paulo: Cengage Learning, 2008.

.MOLION, L. C. B. Aquecimento global, manchas solares, El Niños e Oscilação Decadal do Pacifico. br.geocities.com/zuritageo/aquecimentoglobal.htm Acesso em: 10/07/2008. . Desmistificando o Aquecimento Global. Intergeo, v. 5, p. 13-20, 2007.

.MORIN, E. O despertar da razão. São Paulo: Melhoramentos, 1996.

.NOBRE, Carlos A. Disponível em: $<$ http://www.mudancasclimaticas.andi.org.br/content/carlos-nobre-1>. Acesso em 08/07/2010.

.RUDDIMAN, W. F. Earth's climage: past and future. Washington: Freeman, 2001.

.SERRES, M. Le contrat naturel. Paris: Flammarion, 2000.

.WEART, S.. The Discovery Df Global Warming, 2003. Disponível em: <http://www.aip.org/history/climate> Acesso em: 20 jul. de 2010. 